
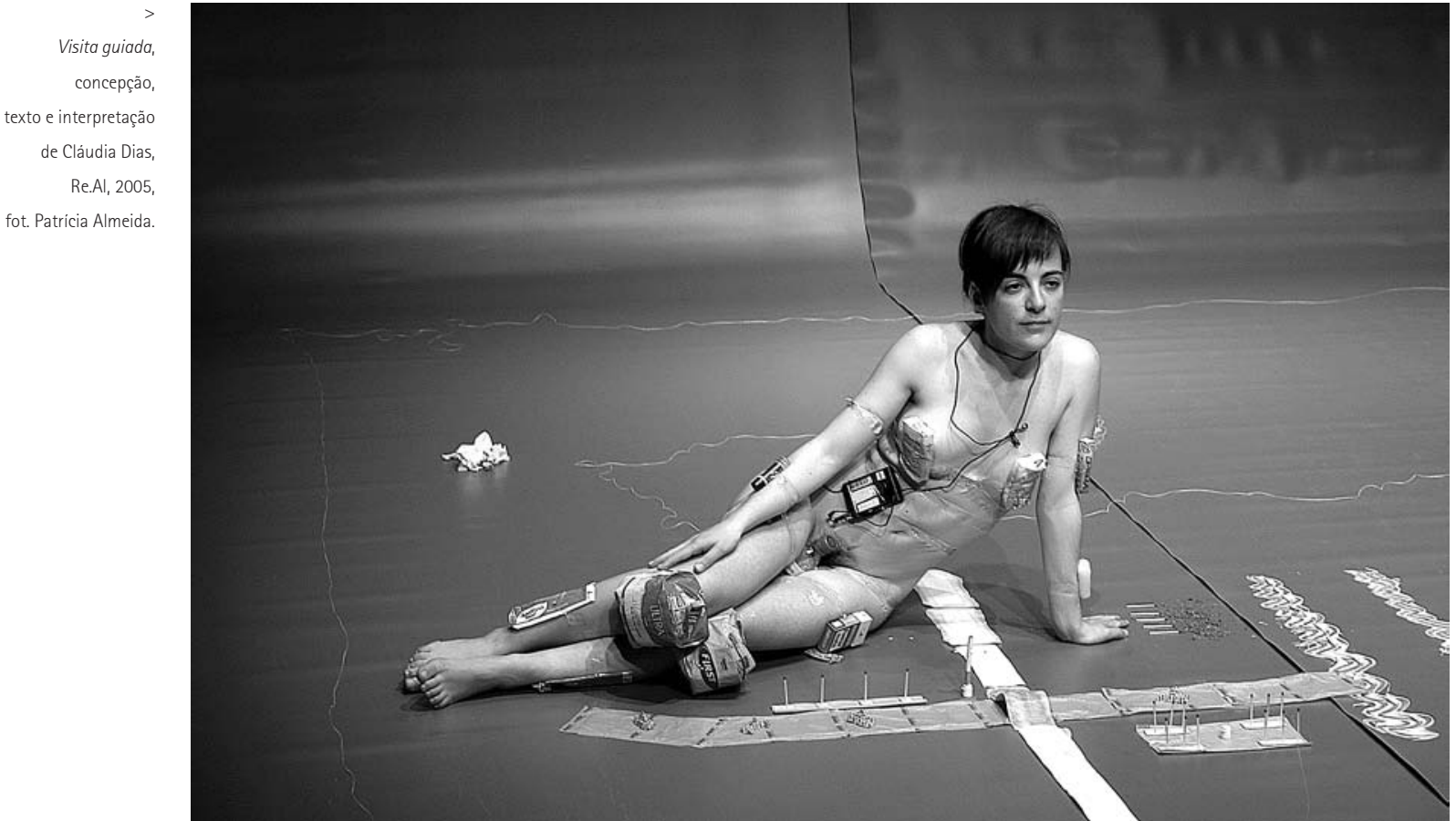

\section{Vale tudo?}

\section{Cláudia Galhós}

Nada é simples. Qualquer realidade considerada para análise implica avaliar diferentes variantes. Isto, que parece óbvio, é frequentemente ignorado nas argumentações em defesa da importância da crítica artística especializada, num tempo em que esta parece estar a desaparecer do espaço público, representado pela imprensa generalista. Das discussões a que assisto, ou que leio, verifico com alguma regularidade que a argumentação se fica por uma lamúria repetitiva, que fala para o umbigo e ignora todo o contexto - a realidade do pais, do mundo, do universo artístico considerado e do jornalismo - que muda de paradigma a cada instante, na vertigem dos tempos contemporâneos. Para qualquer discussão que se queira séria, e não meramente para servir ambições pessoais, é preciso que seja fundamentada numa reflexão sobre este paradigma em mudança, ao nível, pelo menos, de factores como: a realidade das artes performativas contemporâneas em geral; a realidade da criação portuguesa contemporânea em particular; o universo das políticas culturais de apoio às artes, no qual se insere e que também o determina, pelo menos em parte; a economia e a política mundial, nessa angústia permanente da depressão; o papel da comunicação social e a sua realidade actual (fortemente afectada pela crise económica).

$\mathrm{Na}$ impossibilidade de abordar todas as questões aqui propostas, começo por lançar algumas, que considero basilares, e para as quais não possuo ainda respostas definitivas. Que arte é esta de que falamos e que reclama tanta sede por crítica? E que crítica deve ser esta e a quem serve?

Estamos a falar de uma arte que, a cada gesto criativo, recusa a fixação da sua forma, a literalidade da sua interpretação, reflectindo esse rumor da impossibilidade e instabilidade que caracteriza o quotidiano actual. Por isso, qualquer tentativa de a reduzir a um género identificável, a uma definição simples, ou a uma cartilha objectiva e universal de avaliação e descodificação é exercicio demagógico, acto narcísico de quem considera a sua opinião mais válida do que a do seu parceiro. Porque não há regras académicas absolutas para as avaliar. Essa linguagem quotidiana, derramada das ruas para o palco pela dança contemporânea e também pelas formas mais actuais do teatro, faz a apologia da diferença e da beleza da singular imperfeição, humildade, subtileza, fragilidade e contenção, tão próxima da sensibilidade dos artesãos e tão próxima de uma renovada humanidade e singularidade. (Há peças comoventes ou interessantes que situo nesta esfera, como Visita guiada, de Cláudia Dias, Natural, de Clara Andermatt, as peças da Mala Voadora, de Jorge Andrade, entre outras.) Esta pronúncia quotidiana poderia tender a ser transposta para o discurso crítico, que passaria a falar essa mesma linguagem das ruas, mesmo que a partir de um olhar especializado, exercendo essa dificil simplicidade erudita, que aspira a ser partilhada pelo espectador/leitor comum. Afinal, o que hoje está em causa é uma questão de olhar, perspectiva e opinião. Simplesmente, umas são mais fundamentadas do que outras, umas mais esclarecidas do que outras, umas mais honestas do que outras.

Este panorama tem implicações ao nivel do papel desempenhado pelos jornais (que estão mais vocacionados para estruturas narrativas lineares, de fácil compreensão e leitura, e que jogam na transparência do preto ou branco) e também ao nível da reacção do leitor médio, essa suposta comunidade de massa anónima para a qual se escreve nos jornais nacionais. Esse mesmo leitor comum que até gosta destas artes, tem disponibilidade e é curioso, e dá por si 


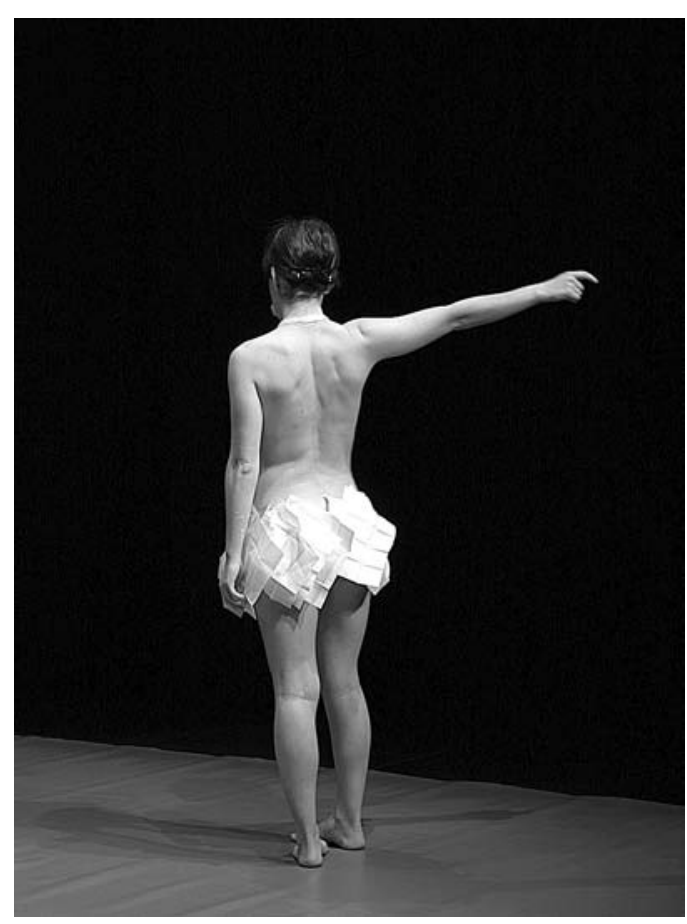

a tentar entrar numa roda de amigos, da qual imediatamente se afasta por perceber que falam uma língua repleta de "piadas internas", das quais não participa. 0 mais natural é que decida rapidamente sair da roda. E se a conversa se mantém interna, fechada nessa roda intima, não vejo por que motivo se deve reclamar que ela decorra na esfera do espaço público. Aqueles de nós que se consideram civilizados, defendemos que a vida privada deve ser mantida na esfera privada. Certo?

Ou seja, para que não haja equívocos, o que quero dizer é que: para a criação ser totalmente livre (e é da criação contemporânea, experimental, a que corre risco e se questiona permanentemente, que aqui trato), e para poder ter ressonância no espaço público, para o seu valor poder ser reconhecido, e ganhar poder político e legitimidade, cabe a quem escreve (continuemos a falar de críticos, à falta de melhor expressão) intermediar esse diálogo, com um discurso que seja compreensivel. 0 espaço das conversas internas (tão importantes, válidas e fundamentais) tem o seu contexto próprio. Porque a questão do contexto não serve apenas para dar sentido aos objectos artísticos produzidos.

Os artistas que sejam tudo aquilo que quiserem! Porque só assim consigo entender a arte. Que os artistas sejam, porque o são por direito, narcísicos, fechados, alucinados, diletantes, deslumbrados, utópicos, fundamentalistas, cegos, inconsistentes, caóticos, sedutores, esquizofrénicos, incompreensiveis! Para que o possam ser, alguém tem de garantir a leitura desse delírio. A questão é que a comunicação social talvez já não esteja para estas coisas. Talvez se tenha fartado das conversas de umbigo. E talvez, mais importante ainda, os tempos sejam dificeis. E reclamar a responsabilidade cívica dos jornais, ignorando o que se está a passar com este sector, em consequência da transformação do mundo onde vivemos, é puro autismo e ignorância.

Não tenho quaisquer dúvidas do quanto é importante existir uma ressonância, no espaço público, da rica dinâmica artistica que existe actualmente em Portugal nas artes performativas. Não tenho dúvidas que o espaço crítico, de análise, de reflexão, de interpretação, de confronto ou

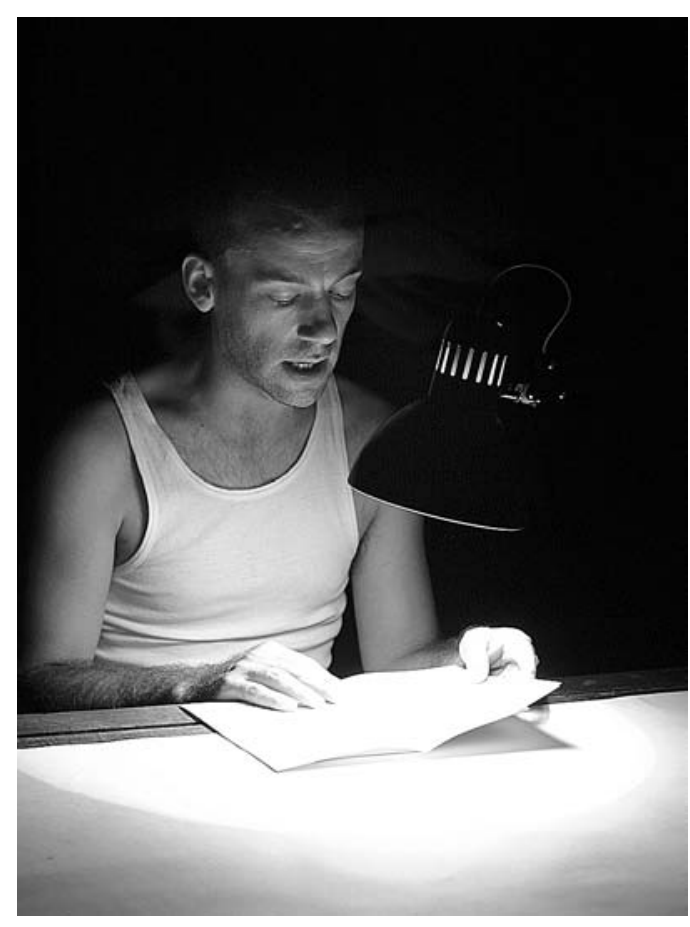

Visita guiada, concepção, texto e interpretação de Cláudia Dias, Re.Al, 2005, fot. Patricia Almeida.

Nicarágua prologue, a partir de Bernard-Marie Koltès, enc. Miguel Loureiro, direcção artistica de Jorge Andrade e José Capela, Mala Voadora, 2004 (Jorge Andrade), fot. Susana Paiva.

diálogo, vai ter de encontrar o seu lugar, talvez um novo lugar, e que tem de ser colocado em plano visivel, em evidência e com rigor - para que as artes que trata possam também aceder a essa atenção e reconhecimento. Tenho muitas dúvidas sobre que espaço será este. Mas pareceme óbvio que a discussão não pode continuar dentro do meio, para o meio, e apenas considerando questões internas do meio, como se fosse indiferente toda esta revolução que se passa no mundo, nas artes e na imprensa. Mais ainda quando estamos mesmo a falar de uma mudança de paradigma. Se não tenho resposta, posso partilhar pistas e alguns factos. Basta olhar para a cronologia das movimentações na comunicação social europeia em finais de Agosto e Setembro de 2006:

A 26 de Agosto, a The Economist dedica a edição ao tema "Quem matou o jornal". Recordava lá dentro, em editorial, as palavras de Arthur Miller, em 1961, quando dizia que "um bom jornal, presumo, é uma nação a falar consigo própria" e fazia o diagnóstico: "No mundo rico, os jornais são agora uma espécie em vias de extinção. 0 negócio da venda de palavras e da venda de leitores a anunciantes, que sustentou o seu papel na sociedade, está a desmoronarse." Lá dentro, no artigo intitulado "Mais media, menos notícias" (note-se que a The Economist é uma publicação emblemática na defesa do papel de intermediário do jornalista, que não deve ceder à tentação de ser protagonista, desde logo porque os textos não são assinados, sendo assumidos como reflectindo a identidade da revista, que defende uma assinatura única, a da própria publicação), traçavam o perfil da mudança:

Depois de ignorar a realidade durante anos, os jornais estão, finalmente, a fazer algo. De modo a cortar custos, já estão a gastar menos no jornalismo. Muitos estão também a tentar captar jovens leitores ao mudar a orientação das suas histórias para o entretenimento, o estilo de vida e os temas que possam parecer mais relevantes para as vidas diárias das pessoas do que as questões internacionais e a politica. Estão a tentar criar novos negócios on e off line. E estão a investir em jornais diários gratuitos, os quais não usam nenhuma das suas magras fontes 
editoriais para descobrir casos de corrupção política ou fraude corporativa. Até agora, parece improvável que este tipo de actividade salve muitos deles. Mesmo que o faça, vai ter consequências negativas para o papel público do Quarto Estado (...) A Internet abriu o mundo fechado dos editores profissionais e repórteres a qualquer pessoa com um teclado e uma ligação à Internet. (...) Cada blogger é capaz de ser tendencioso e calunioso, mas, visto como grupo, os bloggers oferecem, a quem procura a verdade, infindável material para reflectir. Claro, a Internet favorece as mentes fechadas; mas o mesmo também faz muita da imprensa.

A 1 de Setembro, saía, com a primeira página a negro e o título de "Ponto Final", o último número de O Independente. Já nesse ido ano de 1988, no número 0, Miguel Esteves Cardoso traçava o desafio do jornal, que se posicionava contra o hermetismo: "Suspeito que os nossos jornalistas e romancistas incompreensiveis escrevem para serem relidos, interpretados, divididos em orações, enterrados no quintal e redescobertos cinco séculos depois. A clareza, se calhar, parece-Ihes demasiado com a superficialidade". Nesse jornal de despedida, a última crónica de Manuel Falcão ("Um Regime Perigoso"), traçava o panorama da realidade nacional: "Hoje em dia, a imprensa portuguesa está qualitativamente pior que há uns anos, é menos informativa, mais opinativa e, inevitavelmente, perdeu capacidade de iniciativa e desprezou a proximidade aos públicos destinatários".

A 2 de Setembro, em vésperas da grande remodelação - Expresso tornava clara, em editorial, a defesa da sobriedade e do papel de referência, rejeitava a tendência da "tabloidização", num panorama onde parece que vale tudo:

Perante as ameaças, os grandes jornais teriam duas respostas: ou render-se ao sensacionalismo, historietas e rumores, ou persistir em manter-se como o contrapeso, ou o contrapoder, que oferece (além de histórias interessantes e informações úteis) a informação rigorosa para que cada individuo seja um cidadão capaz de tomar opções para a sua vida e para a vida da sua comunidade e pais. No fundo, os jornais optam pelo jornalismo tablóide ou pelo jornalismo de referência. 0 Expresso escolheu clara e obviamente a via que sempre o caracterizou. Seremos como nascemos, um jornal de referência.

A 6 de Setembro, o Diário de Notícias escrevia: "Sol e Expresso a postos para a luta". E a 7, a Visão voltava ao assunto com a "Revolução nos semanários", "Uma remodelação, um lançamento e um fecho agitam a imprensa nacional". Na Sábado, na mesma altura, Miguel Esteves Cardoso escrevia: "Em 2006 é a Internet, ainda muito longe do que será, que ajuda a definir o que um jornal necessário deve ser. Pelo menos três coisas: será temporário; fará por ser guardado (...) o jornal será como um livro da semana; será absolutamente livre".

A 10 de Setembro, o título é do Público: "Revistas TIME e Newsweek à procura de novo fôlego". 0 artigo, de Maria Lopes, dava conta do panorama negro que se vive noutros paises da Europa: "Em poucos meses, as duas maiores revistas semanais de informação mudaram de director e tentam contornar um cenário de redução de quadros, circulação em queda e investimento publicitário estagnado".

Na mesma edição, escrevia-se: "Londres vai ter semanário desportivo gratuito no fim do mês"; e, também: "Trabalhadores do La Vanguardia defendem postos de trabalho". A 11 de Setembro, o Público dá conta da saída em França de um livro fundamental para esta discussão, La situation des esprits, escrito por Jean-Philippe Domeca e Éric Naulleau (Éditions de La Martinière). Uma longa conversa, contra o "conformismo das ideias feitas", onde falam da "depressão cultural", da arte contemporânea que definem como "recent art", e defendem que a crise das artes, da literatura e da política "que perdura desde há um quarto de século" é "alimentada por todos aqueles que têm por tarefa escrever sobre ela". Depois surge a boa notícia de que o Correio da Manhã vai ter novos suplementos, ainda se ouve falar de um de cultura, mas rapidamente se percebe que não é bem assim e temos o "Sport", o "Êxito" (música e espectáculos) e o "Vidas". Mas também a revista do novo jornal Sol chama-se "Tabu". 0 nome diz muito.

A 13 de Setembro, o mesmo Público escreve: "Director adjunto do El Mundo passa a dirigir site"; e ainda:

"Lusomundo Media estuda lançamento de gratuito". A 15 de Setembro, o suplemento de economia do Público, "Dia D", também se dedica ao assunto quente: "0 futuro dos jornais". No artigo "A revolta dos jornais", José Manuel Fernandes (director do Público), em declarações à jornalista Blandina Costa, traça o panorama do momento: "Se há dez [anos] foi preciso introduzir mudanças para facilitar a leitura, hoje os focos estão virados para a edição e para a escolha e abordagem dos temas. A saída, diz, está na aproximação à vida dos cidadãos, tratando de forma séria assuntos que interessam às pessoas e que dominam as conversas do dia-a-dia".

0 mesmo artigo aponta as causas da crise: o peso da Internet como uma das maiores fontes de informação; 0 sucesso dos jornais gratuitos; a queda das receitas de publicidade. A 23 de Setembro, é o DN quem avança com o número de 50 trabalhadores, muitos deles jornalistas, que o Público vai despedir, citando o comunicado interno:

A persistência dos factores negativos que têm vindo a afectar a imprensa diária, tanto em Portugal como no mundo desenvolvido - perda de circulação e quebra nas receitas publicitárias, assim como os maus resultados registados no primeiro semestre de 2006 (EBITDA negativo de 2,66 milhões de euros) - são as razões que levaram o Público a

lançar aquilo que chamou de "uma verdadeira reinvenção do jornal".

Isto é apenas uma infima parte do que se passa no jornalismo. Mas, perante tudo isto, como é possível reclamar lugar para a crítica sem olhar para o mundo que muda? As respostas talvez ainda estejam por ser encontradas, mas há muitas questões que não se podem ignorar, com o risco de se ficar a falar sozinho até à morte que, pelos vistos, já ronda. 